\title{
Caregiver Burden in the Management of Frail Elderly Patients with Diabetes in Internal Medicine
}

\author{
José Miguel Seguí Ripoll1,2*, Vicente Jesús Seguí Llinares³, Miguel J. Reig Pérez³, \\ Carles García Cervera ${ }^{1}$, Juan Manuel Núñez Cruz ${ }^{1}$, Pedro Esteve Atiénzar ${ }^{1}$, \\ Sara Bañón Escandell ${ }^{1}$, Alberto López Serrano', María Dolores Jover Ríos ${ }^{4}$, \\ Juan Méndez Mora5 , Carmen Seguí Pérez ${ }^{5}$, María Josefa Navarro Navarro6, Pablo Roig Rico ${ }^{1,2}$ \\ ${ }^{1}$ Department of Internal Medicine, University Hospital of San Juan, Alicante, Spain \\ ${ }^{2}$ Department of Clinical Medicine, Miguel Hernández University, Elche, Spain \\ ${ }^{3}$ Institute of Design and Manufacturing, Polytechnic University of Valencia, Campus of Alcoy, Alicante, Spain \\ ${ }^{4}$ Department of Internal Medicine, Hospital La Vega Baja of Orihuela, Alicante, Spain \\ ${ }^{5}$ Secondary School, Marist Brothers High School, Alicante, Spain \\ ${ }^{6}$ Primary Medicine, Benilloba, Spain \\ Email: *jsegui@umh.es
}

How to cite this paper: Ripoll, J.M.S., Llinares, V.J.S., Pérez, M.J.R., Cervera, C.G., Cruz, J.M.N., Atiénzar, P.E., Escandell, S.B., Serrano, A.L., Ríos, M.D.J., Mora, J.M., Pérez C.S., Navarro, M.J.N. and Rico, P.R. (2018) Caregiver Burden in the Management of Frail Elderly Patients with Diabetes in Internal Medicine. Health, 10, 1383-1391.

https://doi.org/10.4236/health.2018.1010107

Received: September 25, 2018

Accepted: October 22, 2018

Published: October 25, 2018

Copyright $\odot 2018$ by authors and Scientific Research Publishing Inc. This work is licensed under the Creative Commons Attribution International License (CC BY 4.0).

http://creativecommons.org/licenses/by/4.0/

\section{c) (i) Open Access}

\begin{abstract}
Aim: Advanced age and fragility often lead to dependence, making caregiver assistance necessary for performing the activities of daily living. Patients with diabetes are characterized by an elevated presence of comorbidities and subsequent frailty-a relevant consideration when making decisions regarding treatment goals. Health professionals may overlook the caregiver experience when assessing the circumstances surrounding frail elderly patients with diabetes, but this factor can have a large impact on relevant caregiver and patient outcomes. Methods: An observational, retrospective study was carried out to assess the impact of improved management in diabetes on caregiver burden. We assessed patients' performance of activities of daily living using the Barthel scale. Our primary outcome was caregiver burden, as assessed using the Zarit scale. Results: At baseline, $81.4 \%$ of the caregivers reported severe overburden ( $>55$ points on the Zarit scale). At three months, the proportion of caregivers reporting this level of burden had dropped to $76.7 \%$ and remained stable at six months (77.1\%). In contrast, $8.5 \%$ of the caregivers reported moderate overburden ( 47 to 55 points) at baseline, compared to $13.3 \%$ at three months and $12.5 \%$ at six. The proportion of caregivers reporting no overburden ( $<47$ points) was similar at all time points $(10.2 \%, 10.0 \%$ and $10.4 \%$ at baseline, three months and six months, respectively). Conclusions: Caregiver burden remained persistently high, decreasing only slightly after six
\end{abstract}


months.

\section{Keywords}

Elderly, Diabetes, Frail Patient, Overload, Caregiver

\section{Introduction}

The number of people with one or more disability increases with age, reaching about $63 \%$ in those aged 80 or older. Approximately $30 \%$ of people in this age group have difficulties moving from one place to another, and another $30 \%$ need help to take care of themselves. Furthermore, over $96 \%$ of people with some level of dependence have at least one chronic disease, and $73.3 \%$ are aged 65 or older [1]. Thus, dependence is associated with advanced age; is a consequence of fragility [2] [3], and entails some degree of support from others (caregivers) to carry out, supplement and assist in activities of daily living [4].

Chronic disease affects the lives of patients but also those of their caregivers. Indeed, the literature describes a direct relationship between the high demand for care and the clinical problems of patients with chronic disease, on the one hand, and the overburden borne by their caregivers, on the other. Caregiver burden can have negative effects on health [5], especially on mental health (mainly anxiety and depression), although it is also associated with physical complaints (back pain, headache and muscle pain). Moreover, the convergence of social isolation, lack of free time, family strife and a deteriorating economic situation have given rise to what some authors call "caregiver syndrome". This condition has a negative impact on caregivers' quality of life, necessitating a comprehensive approach that encompasses care for both patients and the people who look after them [5].

This paper examines the specific case of diabetes. The prevalence of type 2 diabetes mellitus (DM) is rising and today represents a serious public health problem [6]. Patients with diabetes are characterized by peculiarities that have implications for both diagnosis and management. The elevated presence of comorbidities, their associated treatments (multidrug therapy), geriatric syndromes (depression, cognitive impairment, falls), urinary incontinence, functional disabilities, clinical heterogeneity and high risk of hypoglycemia [7] make this population a frail one-a relevant consideration when making decisions regarding treatment goals and the use of medication. However, health professionals frequently overlook the caregiver experience when assessing the circumstances surrounding frail elderly patients with diabetes, and this factor may have a large impact on relevant caregiver and patient outcomes, such as health status and quality of life [5]. To date, the role of caregivers and their influence on diabetes have still not been fully elucidated.

Our group has previously published an observational retrospective cohort 
study in 60 frail elderly diabetic patients with comorbidities (mean Charlson index, adjusted for age, $8.0 \pm 2.3$ ) with better metabolic control with insulin glargine six months after discharge [8]. The present study aims to assess the impact of this improved management on caregiver burden (primary outcome) in order to inform the development of a comprehensive approach to this kind of population. Does improved control of diabetes in these patients translate into a lower burden on the caregiver?

\section{Materials \& Methods}

This observational, retrospective, single-center study was carried out in the Department of Internal Medicine of the San Juan University Hospital (Alicante, Spain) between July 2010 and March 2012, with statistical support from the Polytechnic University of Valencia. Research conduct was in accordance with the Guidelines for Good Practice in Pharmacoepidemiology of the International Society of Pharmacoepidemiology (ISPE) and the Declaration of Helsinki, its amendments and national regulations, and it was approved by the Ethics Committee of the San Juan University Hospital (Alicante, Spain. Study code: 12/302). All main caregivers or relatives gave their written informed consent on behalf of the patients.

\subsection{Patient Population and Caregivers}

Inclusion criteria for patient-caregiver pairs were: patients older than 75 years, diagnosed with diabetes mellitus type 2, with a Barthel index of 60 or less, with at least six months' follow-up post-discharge, and signed informed consent after agreeing to participate in the study. Recruitment took place over 18 months. The main exclusion criteria were patients diagnosed with type 1 diabetes, treated with corticosteroids and with systemic disease.

\subsection{Assessments}

We retrieved data from patients' medical records at baseline (hospital discharge), an intermediate time point (three months) and at six months' follow-up. We assessed patients' performance of activities of daily living using the Barthel scale [9] (an index containing 10 items focusing on the patient's level of dependence on aid, as a widely validate tool used to estimate physical dependence of elderly and physically disabled) and also collected data on social, demographic and clinical variables for both patients and caregivers. Our primary outcome was caregiver burden, as assessed using the Zarit scale [10], a validated tool to measure and assess this outcome. The original 22-item self-administered tool was first used in cross-sectional, longitudinal intervention studies in caregivers of people with dementia. Each item is answered using a Likert scale with a range of choices from 0 (never) to 4 (nearly always) and a total possible score of 88. Higher scores represent higher perceived burden. Using this scale, the care-giver experience is classified as "without burden" (below 47 points), "mild 
burden" (47 - 55 points), and "severe burden" (higher than 55 points).

\subsection{Statistical Analysis}

We expressed quantitative variables as means and standard deviation (SD) and qualitative variables using frequencies and proportions. We compared quantitative variables at baseline and follow-up using t-tests, the Wilcoxon test or Mann-Whitney test, and we used the chi-square test, Fisher's exact test, paired proportion test or McNemar test for qualitative variables. Missing data were not considered in the analyses, and we considered $\mathrm{p}$ values of less than 0.05 to be statistically significant. All statistical analyses were performed SPSS software, version 17.0 (SPSS Inc., Chicago, IL, USA).

\section{Results}

Table 1 presents patient and caregiver characteristics at baseline ( $\mathrm{n}=60$ caregiver-patient pairs, with no withdrawals).

\subsection{Caregiver Characteristics}

Caregivers had a mean (SD) age of $59.9 \pm 16.7$ years, and $63.3 \%$ were women. They dedicated an average $10.7 \pm 7.2$ hours per day to caregiving activities. Lost wages had an estimated value of $500 €$ to $1499 €$ or $1500 €$ to $1999 €$ for $40.9 \%$ of caregivers (in each income bracket). Thirty-three patients had applied for an economic subsidy to cover dependence care, but only two were receiving it at the time of the study. Only 12 patients had social support at home.

\subsection{Patient Characteristics}

The 60 patients included in the analysis had a mean age of $83.1 \pm 4.9$ years, and $63.3 \%$ were men. Sixty-three per cent of patients lived at home, while the rest spent at least part of their time in an assisted living facility. Those living in a residence for the elderly had been there for an average of $3.5 \pm 1.7$ years. All patients were polymedicated (mean number of drugs at hospitalization $10.9 \pm 2.6$ ). Mean length of hospital stay at study baseline was $10.6 \pm 6.6$ days. At this time point, $60 \%$ showed a high level of dependence (Barthel index $<20$ ) (Figure 1 ).

Mean albumin at baseline was $2.5 \pm 2.1 \mathrm{~g} / \mathrm{dL}$. At discharge, $70 \%$ of the patients were prescribed oral nutrition; 25\%, nasogastric tube; and 5\%, percutaneous endoscopy gastrostomy.

\subsection{Primary Outcome: Caregiver Burden}

Upon discharge (baseline), $81.4 \%$ of the caregivers reported severe overburden ( $>55$ points on the Zarit scale). At three months, the proportion of caregivers reporting this level of burden had dropped to $76.7 \%$ and remained stable at six months $(77.1 \%)$. In contrast, $8.5 \%$ of the caregivers reported moderate overburden (47 to 55 points) at baseline, compared to $13.3 \%$ at three months and $12.5 \%$ at six. The proportion of caregivers reporting no overburden $(<47$ points) was 
Table 1. Baseline characteristics $(n=60) .{ }^{*}$ Valid percentages. SD: standard deviation.

\begin{tabular}{|c|c|}
\hline Caregiver characteristics $(n=60)$ & Value \\
\hline Age (years), mean $\pm S D$ & $59.9 \pm 16.7$ \\
\hline \multicolumn{2}{|l|}{ Gender, $\mathrm{n}(\%)$} \\
\hline Male & $22(36.7)$ \\
\hline Female & $38(63.3)$ \\
\hline \multicolumn{2}{|l|}{ Relationship, n(\%) } \\
\hline Wife & $18(30)$ \\
\hline Husband & $6(10)$ \\
\hline Daughter & $19(31.7)$ \\
\hline Son & $13(21.7)$ \\
\hline Other & $4(6.7)$ \\
\hline \multicolumn{2}{|l|}{ Marital status, $n(\%)$} \\
\hline Married & $46(76.7)$ \\
\hline Single & $6(10)$ \\
\hline Divorcee & $6(10)$ \\
\hline \multicolumn{2}{|l|}{ Caregiver education, $\mathrm{n}(\%)$} \\
\hline Degree & $13(21.7)$ \\
\hline Technical certificate & $11(18.4)$ \\
\hline School studies & $15(25)$ \\
\hline \multicolumn{2}{|l|}{ Occupational status, $\mathrm{n}(\%)$} \\
\hline Employee & $18(30)$ \\
\hline Unemployed & $10(16,7)$ \\
\hline Caregiver & $27(45)$ \\
\hline Time (hours/day) to care, mean \pm SD & $10.7 \pm 7.2$ \\
\hline Patient characteristics $(n=60)$ & Value \\
\hline Age(years), mean $\pm S D$ & $83.1 \pm 4.9$ \\
\hline \multicolumn{2}{|l|}{ Gender, $\mathrm{n}(\%)$} \\
\hline Male & $38(63.3)$ \\
\hline Female & $22(36.7)$ \\
\hline Hospital stay (days), mean \pm SD & $10.6 \pm 6.6$ \\
\hline Time from diagnosis (years), mean \pm SD & $14 \pm 7.6$ \\
\hline Hypertension & $58(96.7)$ \\
\hline Hypercholesterolemia & $31(54.4)$ \\
\hline \multicolumn{2}{|l|}{ Diabetes complications, $\mathrm{n}(\%)$} \\
\hline Pressure sore & $35(58.3)$ \\
\hline Nephropathy & $34(56.7)$ \\
\hline Cerebrovascular accident (CVA) & $32(53.3)$ \\
\hline Retinopathy & $18(30)$ \\
\hline Intermittent claudication & $14(23.3)$ \\
\hline Diabetic foot & $11(18.3)$ \\
\hline Artertial Periferic Disease & $5(8.3)$ \\
\hline Neuropathy & $4(6.7)$ \\
\hline Number of drug taken, mean $\pm S D$ & $10.9 \pm 2.6$ \\
\hline Charlson index, mean $\pm S D$ & $4.1 \pm 2.3$ \\
\hline Charlson index adjusted by age, mean $\pm S D$ & $8 \pm 2.3$ \\
\hline
\end{tabular}




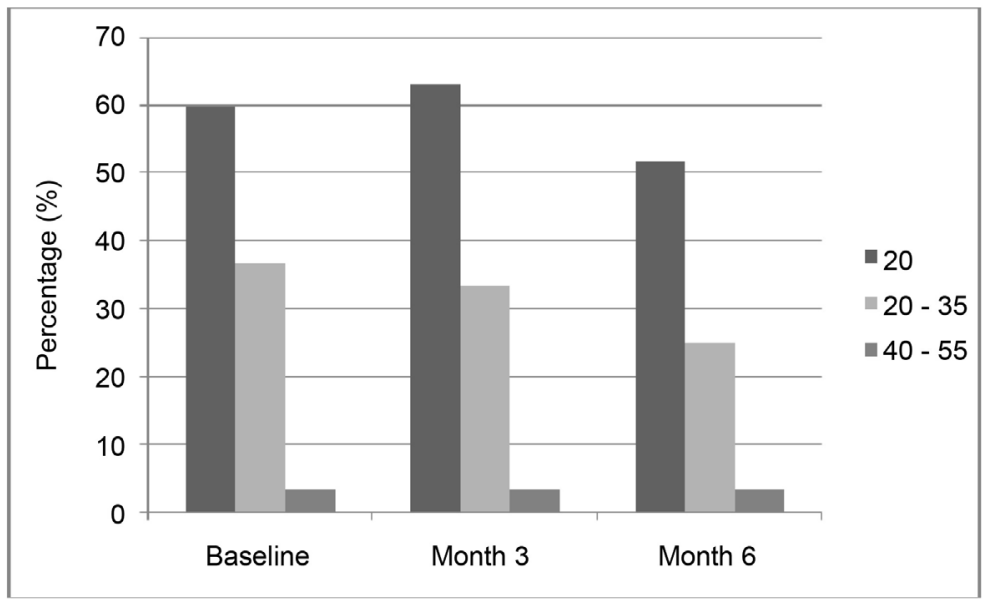

(a)

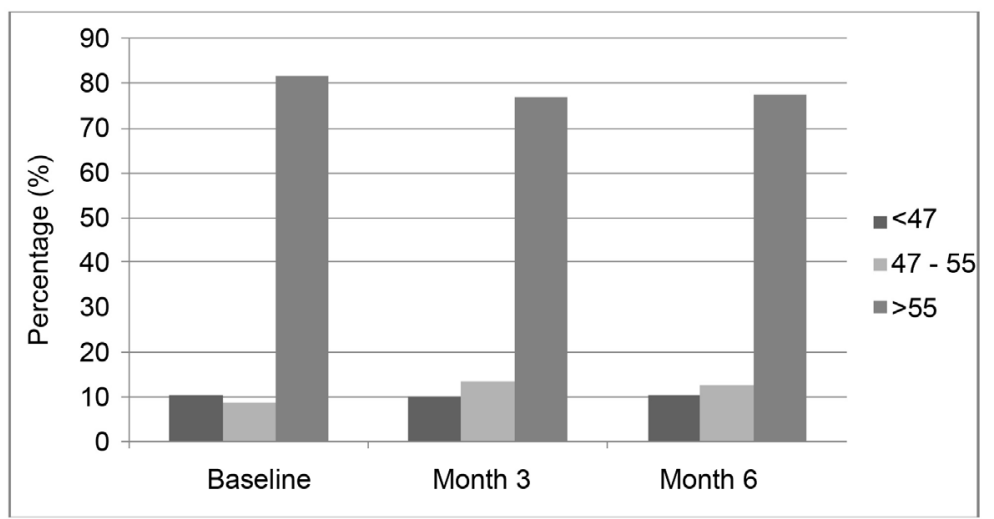

(b)

Figure 1. Index scores used during the study. (a) Barthel score [9]. (b) Zarit score [6].

similar at all time points $(10.2 \%, 10.0 \%$ and $10.4 \%$ at baseline, three months and six months, respectively) (Figure 1). We tested the association between time dedicated to care and Zarit scores, finding a statistical relationship $(\mathrm{r}=0.012 ; \mathrm{p}<$ 0.05).

\section{Discussion}

The impact of the burden overload on caregivers of multipathological patients can be high (40\%), especially if they perceive caregiving to be stressful. Overburden has an important effect on caregivers, putting them at higher risk for the worsening of their own chronic conditions, development of new ones, ischemia, and even death. However, caregiver burden also affects the people under their care and is associated with higher rates of institutionalization and functional deterioration [4] [11].

The specific burden associated with diabetes is also important for the caregiver and may depend to some extent on the patient's treatment. Simple treatment algorithms (whether used by clinicians or caregivers) may contribute to achieving adequate metabolic control and to avoiding negative side effects such as hy- 
poglycemia. Our study is the first to our knowledge that describes a group of frail elderly diabetic patients and their caregivers' overburden. Clinical trials often exclude or omit these populations, and consequently evidence regarding outcomes relevant to them is scarce. Our patients were very elderly (mean age $83.1 \pm 4.9$ years) and multipathological (median Charlson index $8.0 \pm 2.3$ ), and they presented a high degree of dependence, often requiring complex care from physicians, nurses and caregivers. Comorbidities included advanced dementia (Alzheimer's disease, vascular dementia, cognitive impairment, etc.), and patients tended to be bedridden or have limited mobility. Thus, their care required considerable time and effort, since they generally needed help for many-if not all—of the basic activities of daily living, as well as for the supervision of medication, transitions from bed to chair/armchair, etc. They were also very prone to complications that gave rise to a great demand for medical and nursing care and frequent hospital admissions. In addition, these multipathological patients frequently pose ethical problems for those making decisions on whether to limit therapeutic efforts, such as artificial feeding through a tube (often nasogastric tube) or the use of antimicrobials against infections that are secondary to the advanced nature of their clinical situation.

Despite improving metabolic control in these patients, simplifying their antidiabetic treatment, reducing hypoglycemia, and even optimizing their nutrition, caregiver burden remained stubbornly high, decreasing only slightly after six months. Obviously our department, together with the caregivers, were managing an extremely frail diabetic population, and the literature has already described the associations between comorbidities, psychological burden, care complexity and progression of the concomitant diseases [12] [13].

Regarding caregiver burden, our results confirm the large impact that this activity has on caregivers. Thus, we recommend work towards integrating care for caregivers into a comprehensive approach to dependent and frail patients [14], spanning social care services as well primary and specialized health care. Further research into this area could help delineate a more precise profile of caregivers in our context, the variability contained therein, the impact derived from caregiving, and the different needs that these people have. Such knowledge could inform the development of tools to support caregivers more effectively.

Care for caregivers should be considered from the first consultations with patients and provided whenever needed, in parallel with the patient's evolution. The approach should be multidisciplinary, with the participation of all the health professionals involved in patient care.

This study is a descriptive analysis and presents valuable information about the caregiver situation. We did not observe a significant decline in caregiver burden despite improvements in patient outcomes ( $p>0.05$ ), perhaps due to an insufficient follow-up period for detecting significant changes in burden.

Based on our results, there is an urgent need for designing and implementing techniques that ease, improve or support caregivers in their labor. These inter- 
ventions could be to some extent tailored according to the functional dependence and healthcare needs of the people they look after. The caregivers of multipathological, frail, elderly people may require emotional, social, financial and health-related interventions. Effectively addressing their needs will allow them to continue to look after their charges without compromising their own well-being. Caregivers are more than just a healthcare resource; they are also priority recipients for health and social services, as the people who receive their assistance also depend on their caregivers' health.

\section{Conflicts of Interest}

None of the authors have personal conflict of interest nor have they received payments for the performance of this work.

\section{Description of Authors' Roles}

J.M. Seguí designed the study, supervised the data collection and wrote the paper. V.J Seguí and M.J. Reig were responsible for the statistical design of the study and for carrying out the statistical analysis. C. García, J.M. Núñez, S. Bañón, A. López, P. Esteve, M. D. Jover, J. Méndez, M. J. Navarro and P. Roig collected the data and assisted with writing the article.

\section{Sponsor's Role}

None.

\section{References}

[1] Barnett, K., et al. (2012) Epidemiology of Multimorbidity and Implications for Health Care, Research and Medical Education: A Cross-Sectional Study. The Lancet, 380, 37-43. https://doi.org/10.1016/S0140-6736(12)60240-2

[2] Xue, Q.L. (2011) The Frailty Syndrome: Definition and Natural History. Clinics in Geriatric Medicine, 27, 1-15. https://doi.org/10.1016/j.cger.2010.08.009

[3] Fulop, T., Larbi, A., Witkowski, J.M., McElhaney, J., Loeb, M., Mitnitski, A., et al. (2010) Aging, Frailty and Age-Related Diseases. Biogerontology, 11, 547-563. https://doi.org/10.1007/s10522-010-9287-2

[4] Douglas, S.L., Daly, B.J., Kelley, C.G., O’Toole, E. and Montenegro, H. (2005) Impact of a Disease Management Program upon Caregivers of Chronically Critically Ill Patients. Chest, 128, 3925-3936. https://doi.org/10.1378/chest.128.6.3925

[5] Margaret Longacre, L. (2014) An Integrative Review of U.S. Studies: Caregiver Psychological Health and Hospitalization Characteristics of Older Adult Care Recipients. Research in Gerontological Nursing, 7, 139-147. https://doi.org/10.3928/19404921-20140127-01

[6] Helmer, D., Tseng, C.L., Wrobel, J., Tiwari, A., Rajan, M., Pogach, L., et al. (2011) Assessing the Risk of Lower Extremity Amputations Using an Administrative Data-Based Foot Risk Index in Elderly Patients with Diabetes. Journal of Diabetes, 3 , 248-255. https://doi.org/10.1111/j.1753-0407.2011.00135.x

[7] Munshi, M.N., Maguchi, M. and Segal, A.R. (2012) Treatment of Type 2 Diabetes in the Elderly. Current Diabetes Reports, 12, 239-245. 
https://doi.org/10.1007/s11892-012-0269-4

[8] Seguí Ripoll, J.M., Esteve Atiénzar, P., López Corbalán, J.C., Roig Rico, P., Navarro Navarro, M.J. and Merino Sánchez, J. (2015) Treatment Management and Glycaemic Control in a Sample of 60 Frail Elderly Diabetics with Comorbidities. A Retrospective Chart Review. European Journal of Internal Medicine, 26, 456-457. https://doi.org/10.1016/j.ejim.2015.04.017

[9] Bolaños Abrahante, O., Bravo Acosta, T., Fernández Gutiérrez, D.C., Pedroso Morales, I., Rodríguez Lara, H. and Seoane Piedra, J. (2017) The Use of the Neuro Rehabilitation Treatment in the Functional State in Patients with Ischaemic Ictus. Rev Cubana Medic Fís Rehabilit, 9, 1-9.

[10] Zarit, S.H., Reever, K.E. and Bach-Peterson, J. (1980) Relatives of the Impaired Elderly: Correlates of Feelings of Burden. Gerontologist, 20, 649-655.

https://doi.org/10.1093/geront/20.6.649

[11] Jayani, R. and Hurria, A. (2012) Caregivers of Older Adults with Cancer. Seminars in Oncology Nursing, 28, 221-225.

[12] Martinez Velilla, N.I. and Gaminde, I.I. (2011) Comorbidity and Multimorbidity Indexes in the Elderly Patients. Medicina Clínica, 136, 444-446.

[13] Brown, A.F., Mangione, C.M., Saliba, D. and Sarkisian, C.A. (2003) Guidelines for Improving the Care of the Older Person with Diabetes Mellitus. Journal of the American Geriatrics Society, 51, S265-S280.

[14] Argimon, J.M., Limon, E., Vila, J. and Cabezas, C. (2004) Health-Related Quality of Life in Carers of Patients with Dementia. Family Practice, 21, 454-457.

https://doi.org/10.1093/fampra/cmh418 